\title{
Changes in the Content of Organic Matter in Black soils of Central Ciscaucasia Caused by Their Agricultural Use
}

\author{
Valerii Sergeevich Tshovrebov, Vera Ivanovna Faizova, \\ Dmitry Vasilivich Kalugin, Anastasia Mikhailovna Nikiforova \\ and Vera Yaroslavovna Lysenko
}

Stavropol State Agrarian University, 12, Zootechnichesky Pereulok, Stavropol, 355017, Russia

http://dx.doi.org/10.13005/bbra/2026

(Received: 30 December 2015; accepted: 03 February 2016)

\begin{abstract}
The research of organic matter content in major subtypes of black soils of the Central Ciscaucasia, namely: ordinary carbonated, ordinary regular (not boiling from the surface), leached and alkalized-firm (similar to vertisols) on virgin and on arable soils, has been performed. It has been found that within 70-100 years of soils exploitation in the system of agrobiocenoses, the content of humus in the upper horizons of soils has reduced by 16-38 \% for carbonated, 25 to $33 \%$ for regular, $6-21 \%$ for leached, and 8-24\% for alkalized-firm black soil. This trend has not been observed below the illuvial zone. Humic acids contain significantly less fulvic acids, and the humic to fulvic acids ratio (HA:FA) increases in arable soil, as compared to virgin soils from 1.52 to 2.77 for carbonated, from 1.74 to 2.17 for regular and from 1.72 to 2.00 for leached black soils. In alkalized-firm soils, the difference for this indicator has not been detected.
\end{abstract}

Key words: Organic matter, black soil, Ciscaucasia, humic acids, fulvic acids, virgin soil, tillage.

One of the elements of soils fertility in the modern agriculture is transformation of fresh organic matter, and, first of all, the processes of humus synthesis and mineralization ${ }^{1-5}$. Many researchers ${ }^{6}$ agree that humous soils are characterized by a favorable and ecologically balanced composition of microbian cenoses, buffering capacity, optimal for plants combination of water, air, thermal and nutritious regimes.

Continuous inflow of organic residues and their biochemical transformation into the soils are the necessary conditions for formation of humus $^{7-9}$. It is obvious that organic plant residues inflow into the soils may be balanced only in the conditions of natural ecosystems ${ }^{10-12}$. Alienation of a considerable amount of plants biomass in

\footnotetext{
* To whom all correspondence should be addressed.
}

agrocenoses disturbs the balance of leaf mold inflow into the soils ${ }^{13-15}$.

Biochemical circulation of nutrients in natural ecosystems is nearly of closed type. It is a mechanism of capturing, accumulation, redistribution and consumption of energy by organisms and soil, controlled by the established biocenosis. In these conditions, soils hold a tremendous amount of potential energy that is equal to its content in the aboveground biomass, and accumulate nutrient reserves for many generations of plants. Almost all biological products in natural ecosystems are retained, decomposed and mineralized on the surface and in the soil. Only a small portion (3-4\%) in the form of organic and mineral compounds is removed along with the aboveground and underground flows, and is included into the geological circulation of the planet ${ }^{16-18}$.

Agricultural production is dramatically changing the mechanism of natural ecosystems functioning. First, 20 to $80 \%$ of the organic 
products are alienated as food, fodder, fuel or organic raw materials. This results in openness of substances circulation and in changes in the energy balance of the ecosystem ${ }^{1-21}$. Therefore, soil, reserves of potential energy and important mineral nutrients get gradually depleted ${ }^{22-25}$.

After 50 to 70 years of agricultural use without losing organic fertilizers, most soils lose $20-50 \%$ of humus, as compared to the initial indicators ${ }^{26-30}$.

\section{METHODS}

The research was focused on main subtypes of black soils of the Central Ciscaucasia: ordinary carbonated, ordinary regular (not boiling from the surface), leached and alkalized-firm soils.

Ordinary carbonated black soils occupy the largest area (19.6\%) confined to the Central, the Western and the Northwestern parts of the Central Ciscaucasia. Ordinary regular and leached black soils are located in the center of the Stavropol upland. Loess-like loams are parent rocks for these soils.

Alkalized-firm black soils are located in the Southern and the Southwestern parts of the Mineralovodsk hilly plain that is a part of the Armavir wind corridor. The parent rocks of these soils are highly compacted eluvium and structureless tertiary Maikop clays of marine origin.

Ordinary black and alkalized-firm soils develop in the conditions of unstable humidification. The hydrothermic coefficient (HTC) is 0.9 to 1.1. The sum of active temperatures is in the range of $3000-3400{ }^{\circ} \mathrm{C}$. Winters are relatively cold, with average January temperature of $-4 \ldots-5$ ${ }^{\circ} \mathrm{C}$. The snow cover is unstable. The summer is hot. The average July temperature is $+23-+24^{\circ} \mathrm{C}$, and the maximum temperature is $+42^{\circ} \mathrm{C}$.

Precipitation is short, mostly of rainfall nature. Total precipitation per year ranges between 450 and $500 \mathrm{~mm}$. Total precipitation per period of active temperatures ranges between 300 and 350 $\mathrm{mm}$.

Ordinary and leached regular black soils develop in the more humid conditions. Precipitation is higher by $100-120 \mathrm{~mm}$, the sum of active temperatures is in the range between $2800-3000^{\circ} \mathrm{C}$, and the hydrothermic coefficient is 1.1 to 1.3 .

In our studies, we have dug pits in the soils of typical plots of studied black soils subtypes, using the index method. The content of organic matter was determined in paired sections of virgin and arable land 150-200 meters away from each other. These soils have been used in the arable land for 70 to 100 years.

Virgin vegetation is represented by mixed herbs associations. Almost all zoned crops (wheat, barley, oats, maize, sunflower, beans, etc.) are being sowed in the tillage.

The thickness of the studied upper horizons was as follows: turf $\left(\mathrm{A}_{\text {turf }}\right)$ on virgin soils - in the range of 0 to 10,0 to $12 \mathrm{~cm}$, on tillage $\left(A_{\text {till }}\right)$ $-0-18 \mathrm{~cm}$.

Organic matter content was determined by the Tyurin method in the modification of CRDIAS (the Central Research and Development Institute of Agricultural Support).

Black soils have some differences in the main fertility indicators (Table 1).

Black soils formed on loess-like loams feature relatively favorable physical properties (density of 1.20 to $1.30 \mathrm{~g} / \mathrm{cm}^{3}$ ), and low content of exchangeable sodium (less than 5\%). Nitrate nitrogen content is low to medium, within 25 to 34 $\mathrm{mg} / \mathrm{kg}$, mobile phosphorus content is medium (25 to $30 \mathrm{mg} / \mathrm{kg}$ ), exchangeable potassium content is medium to high.

Among them, leached black soils feature slightly greater density and lower content of exchange potassium. Alkalized-firm soils have negative physical properties, however, they feature high content of exchange sodium (18.5-19\% from the sum of exchangeable bases) and exchange potassium. The amount of exchangeable sodium makes them closer to alkali soils. According to Western classification, they fit into vertisols.

\section{RESULTSAND DISCUSSION}

Studies have shown that all studied black soils were characterized by significantly varying amount of organic substances both by key plots, and within them.

In ordinary carbonated black soils (Figure 1 ), the content of organic matter in the virgin land in the Aturf horizon was $4.67 \%$. In the tillage, this indicator decreased by $1.35 \%$. In horizon A on virgin soil, the amount of organic matter is $4.11 \%$, which exceeds the same indicator in the tillage by $0.64 \%$. 
Down the profile, both in the virgin soils and in the tillage, a regular decrease in the studied parameters has been detected, which reaches 0.59 and $0.62 \%$ in the parent rocks, respectively. It should be noted that the content of organic matter is higher in virgin soils than in the tillage only in layers $\mathrm{A}+\mathrm{B}$. Below horizon $\mathrm{B}$, the difference is not detected, or the tillage even features higher indicators than the virgin soil.
In ordinary regular black soils (figure 2), the trend in organic matter distribution of along the profile and between the virgin and arable land plots is similar to that in carbonated black soils. The distinctive feature is the fact that the total content of organic matter exceeds this indicator in ordinary regular black soils, as compared to carbonated black soils by $1.68 \%$ in virgin soil, and by $0.96 \%$ in the tillage.

Table 1. Main black soils fertility indicators

\begin{tabular}{|c|c|c|c|c|c|c|c|}
\hline Soil & $\mathrm{pH}$ & $\begin{array}{l}\text { Density, } \\
\mathrm{g} / \mathrm{cm}^{3}\end{array}$ & $\begin{array}{l}\text { Porosity } \\
, \%\end{array}$ & $\begin{array}{l}\mathrm{NO}_{3}, \\
\mathrm{mg} / \mathrm{kg}\end{array}$ & $\begin{array}{l}\mathrm{P}_{2} \mathrm{O}_{5}, \\
\mathrm{mg} / \mathrm{kg}\end{array}$ & $\begin{array}{l}\mathrm{K}_{2} \mathrm{O}, \\
\mathrm{mg} / \mathrm{kg}\end{array}$ & $\begin{array}{l}\text { Exchange } \\
\text { sodium, } \\
\% \text { of } \Sigma\end{array}$ \\
\hline Ordinary carbonated black soil & $8.2-8.4$ & $1.20-1.30$ & $54-60$ & $25-30$ & $25-30$ & $300-350$ & $0.8-1.5$ \\
\hline Ordinary regular black soil & $7.6-7.8$ & $1.20-1.27$ & $55-60$ & $30-34$ & $25-30$ & $240-260$ & $2.0-2.5$ \\
\hline Leached black soil & $6.5-6.7$ & $1.30-1.38$ & $52-55$ & $25-35$ & $18-25$ & $180-200$ & $2.5-2.8$ \\
\hline Alkalized-firm black soil & 8.1-8.2 & $1.38-1.50$ & $45-52$ & $15-20$ & $25-30$ & $430-450$ & $18.5-19.0$ \\
\hline
\end{tabular}

Table 2. Qualitative composition of organic matter in black soils of Central Ciscaucasia (in virgin soils - in the 0-12 cm layer, in the tillage - in the 0-18 cm layer)

\begin{tabular}{lllllll}
\hline \multirow{2}{*}{ Soil } & Kind of land & Humus \% & \multicolumn{2}{c}{ Group composition \% } & Relation \\
\cline { 5 - 6 } & & & $\begin{array}{c}\text { Humic } \\
\text { acids }\end{array}$ & $\begin{array}{c}\text { HA:FAfulvic } \\
\text { acids }\end{array}$ & $\begin{array}{c}\text { remain } \\
\text { der }\end{array}$ \\
\hline \multirow{2}{*}{ Ordinary carbonated black soil } & virgin soil & 4.67 & 1.08 & 0.71 & 2.87 & 1.52 \\
& tillage & 3.32 & 0.81 & 0.31 & 2.08 & 2.77 \\
Ordinary regular black soil & virgin soil & 6.35 & 1.52 & 0.87 & 3.96 & 1.74 \\
& tillage & 4.28 & 1.15 & 0.53 & 2.60 & 2.17 \\
Leached black soil & virgin soil & 6.97 & 1.72 & 1.00 & 4.25 & 1.72 \\
& tillage & 5.48 & 1.28 & 0.64 & 3.56 & 2.00 \\
Alkalized-firm black soil & virgin soil & 5.98 & 1.46 & 0.94 & 3.58 & 1.55 \\
& tillage & 4.41 & 0.94 & 0.61 & 2.86 & 1.54 \\
\hline
\end{tabular}

The highest humus content was detected in natural biocenoses of leached black soils (Figure 3). Thus, in the upper turf horizon, its content reaches $6.97 \%$, and gradually decreases downwards to $0.83 \%$ in the rocks. In the tillage, organic material content decreases to $5.48 \%$, or to $1.49 \%$, as compared to the virgin land. In horizon A, humus content in the virgin land is $5.92 \%$; it decreases in the tillage by $0.33 \%$. In the rock, the amount of organic matter is not much higher than that in virgin soil; it is $0.95 \%$. Thus, soils in the virgin plot are classified as medium-humic, and in the tillage - as low-humic.
It is also worth noticing that the amount of organic matter in the studied soils of agrocenosis in the subsurface horizons is higher, or has no significant difference from that in the tillage. The obtained data indicate a considerable increase in the rate of humus mineralization in the agrogenically converted horizon in the conditions of significant decrease of leaf mold.

The content of organic matter in the upper horizon of virgin soils of the alkalized-firm black soils (Figure 4 ) is $5.98 \%$. It is $1.57 \%$ higher than that in the tillage. In horizon $\mathrm{A}$ in the virgin lands, this indicator is $4.39 \%$. It is $0.31 \%$ higher 


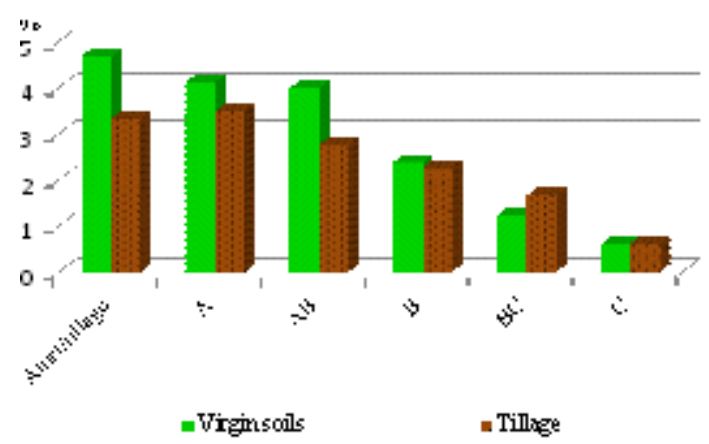

Fig. 1. Variation of humus along the profile of ordinary carbonated black soil

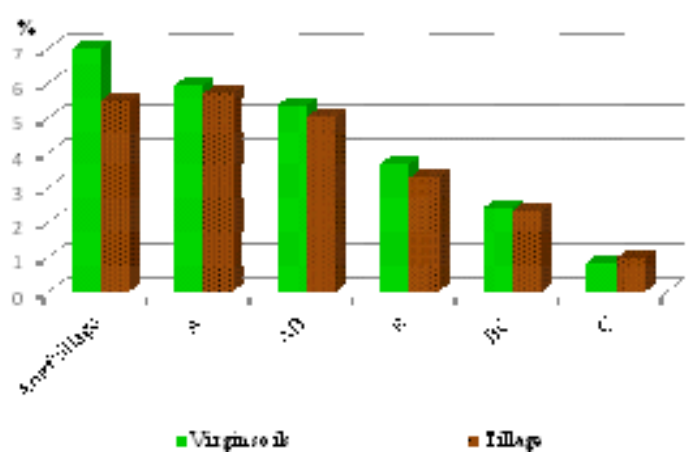

Fig. 3. Changing humus content along the profile of leached black soil

than that in the tillage. Down the profile, natural reduction of its amount occurs towards the parent rock in virgin soils and in the tillage, to $0.47 \%$ and $0.41 \%$, respectively.

In compacted soils, the content of organic matter in the tillage horizon exceeds that in the subsurface horizon. Thus, no evident regularity is observed in the distribution of organic matter between the arable and the subsurface horizons that has been revealed for the ordinary black carbonated, ordinary regular and leached horizons. The reason for this is less active activity of saprophytic microbial flora in the upper arable horizon due to negative physical properties, and less prolonged use of these soils in agricultural production (50 to 60 years). We have studied qualitative composition of humus (Table 2).

In the tillage of ordinary black soil, their content is $0.81 \%$, which is lower, as compared to the virgin lands $25 \%$. The content of fulvic acids

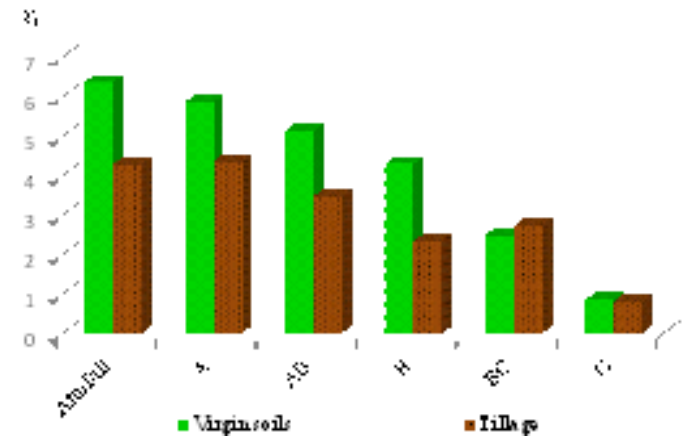

Fig. 2. Variation of humus along the profile of ordinary regular black soil

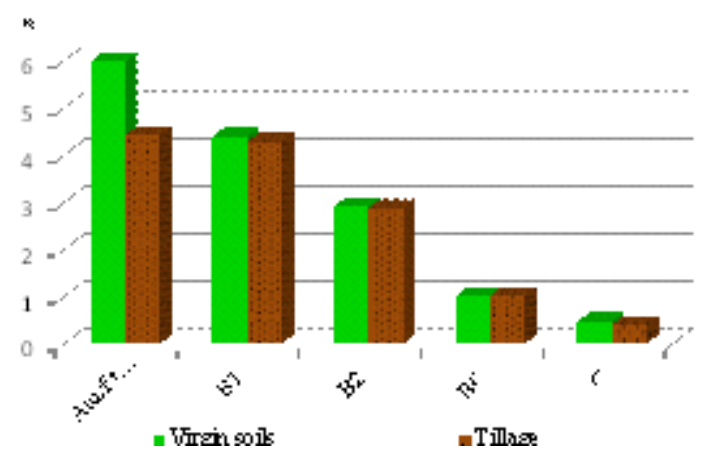

Fig. 4. Changes in humus content along the profile of alkalized-firm black soils

in the tillage is $0.31 \%$, which is 2.3 times lower, as compared to the virgin soil. This confirms the opinion of some scholars that fulvic acids are less resistant to degradation ${ }^{31-32}$.

A similar situation is observed on other subtypes of black soils. The alkalized-firm black soils are somewhat different. Here the difference between virgin soils and the tillage for humic acids is $0.44 \%$, while for fulvic acids, it is $0.41 \%$.

The humus is humate and fulvatehumate. The humic to fulvic acids ratio (HA:FA) in the virgin lands for all studied subtypes of black soils is within $1.52-1.74$. Due to the decreased share of fulvic acids, the HA:FA ratio increases in the tillage. It increases to a greater extent in the ordinary carbonated black soils (2.77) and to a lesser extent in the ordinary regular (2.17) and leached (2.00) soils. In the alkalized-firm black soils, ratio of humic to fulvic acids varies weakly between the virgin soils and the tillage. 


\section{CONCLUSION}

As can be seen from the above, plowing of black soils results in a reduced amount of organic matter in the upper soils horizons. This is the result of disturbed leaf mold cycle, and accumulation and mineralization of organic matter. The studied indicator decreases mainly in the $\mathrm{A}+\mathrm{B}$ horizons. This trend was not observed below the illuvial zone. In addition, the organic matter content in the subsurface horizons of the ordinary carbonated, ordinary regular and leached black soils is higher than that in the tillage horizons. Once again, this fact confirms accelerated degradation of the upper soils horizon that is the most saturated with root systems and microorganisms. It can be assumed that along with degradation of organic matter, degradation of mineral rock of soils occurs due to aggravation of the weathering processes.

\section{REFERENCES}

1. Dorozhko, G.R., A.I. Viyskovoy, N.S. Golousov, V.M. Perederiyeva, O.I. Vlasova and Y.A. Kuzychenko, Stavropol: Agriculture of the Stavropol Territory 2004; 288.

2. Biswas, S., N.B. Choudhuri and P.K. Mukhopadhyay. "Transformations of humus carbon in Aila affected soils of Sunderban in eastern Indian mangrove region Middle East". Journal of Scientific Research, 2013; 15(3): 452460.

3. Adani, F., P. Genevini, F. Tambone and E. Montoneri, "Compost effect on soil humic acid: NMR study.” Chemosphere, 2006; 65: 14141418.

4. Vlasova, O.I., G.R. Dorozhko, V.M. Peredereeva, I.A. Volters and A.I. Tuikov, Improving sustainability of the agricultural ecosystem in Central Caucasus. Bulletin of the Stavropol AIC, 2015; 1(17): 185-190.

5. Kononova, M.M., Soil organic matter. Its nature, properties, and methods of studying. Moscow: The Publishing House of the Academy of Sciences of the USSR, 1963; 614.

6. Tskhovrebov, V.S., V.I. Faizova, V.D. Kalugin, A.M. Nikiforova and A.A. Novikov, Evolution and degradation of Black Soils of Central Caucasus. Bulletin of the Stavropol AIC, 2012; 3(7): 123-125.

7. Klyushin, P.V., A.A. Novikov and A.N. Maryin, Environmental monitoring of chernozems humus status. Evolution and degradation of soil: Proceedings of the III International ScientificPractical Conference, 2007; 93-95.

8. Slyusarev, V.N., L.M. Onischenko and T.V. Shvets, Characteristics of some aspects of leached black soils fertility in Western Ciscaucasia. Polythematic Internet Electronic Scientific Journal of the Kuban State Agrarian University, Krasnodar, 2013; 89: 916-932.

9. Shevchenko, D.A., A.N. Osaulko, L.T. Kretov and A.Yu. Perov, The results of studying degraded soils of the North-Western part of the Stavropol Upland and proposals for protection. Bulletin of the Stavropol AIC, 2013; 1: 32-35.

10. Schmidt, M.W.I., M.S. Torn, S. Abiven, T. Dittmar, G. Guggenberger, I.A. Janssens, M. Kleber, "TrumborePersistense of soil organic matter as an ecosystem property”. Nature 2011; 478: 49 -56.

11. Tskhovrebov, V., Agrogenic degradation of black soils in Central Ciscaucasia. - Stavropol: the Publishing House StSAU “Agrus”, 2003; 224.

12. Ollier, K., Weathering (Translation from English). Moscow: Nedra, 1987; 348.

13. Marschner, D., S. Brodowski, A. Dreves, G. Gleixner, A. Gude, P.M. Grootes, U. Hamer, "How relevant is recalcitrance for the stabilization of organic matter in soils?” J. Plant Nutr. Soil Sci, 2008; 171: 91-110.

14. Kovda, V.A., Soil Cover: improving, use and protection. Moscow: Nauka, 1981; 182.

15. Terpelets, V.I., V.P. Vlasenko and A.V. Osipov, Modern soil formation processes in hydro metamorphosed West Ciscaucasia soils. Proceedings of the Kuban State Agricultural University, 2012; 5(38): 38.

16. Podkolzin, A.I., A.A. Novikov, A.D. Fursov and V.V. Voloshina, The balance of organic matter in the agriculture of the Stavropol Territory. Evolution and Degradation of Soil: Proceedings of the III International Scientific-Practical Conference, 2007; 275-279.

17. Esaulko, A.N. and V.V. Ageev, Improving the system of fertilizers in crop rotation in the Central Ciscaucasia. Agrochemical Messenger, 2005; 4 : 7.

18. Šimanský, V. and N. Pollakova, "Soil organic matter and sorption capacity under different soil management practices in a productive vineyard”. Archives of Agronomy and Soil Science, 2014; 60(8): 1145-1154.

19. Oades, J.M., "The retention of organic matter in soils”. Biogeochem, 1988; 5: 35 - 70.

20. Odum, E.P., “The strategy of ecosystem development”. Science, 1969; 164, 3877: 262270. 
21. Stolt, M.H. and D.L. Lindbo, "Soil organic matter”, Interpretation of micromorphological features of soils and regoliths. Eds., Stoops, G., V. Marcelino and F. Mees. Amsterdam: Elsevier Features, 2010; 17: 369-396.

22. Esaulko, A.N., Y.A. Grechishkina and O.A. Podkolzin, Changing agrochemical indicators of clack soil leached under the influence of optimization of fertilizers systems in crop rotation. Problems of Agrochemistry and Ecology, 2009; 1: 3-7.

23. Esaulko, A.N., A.A. Podkolzin and M.S. Sigida, Monitoring of soil fertility in the Stavropol territory. Evolution and degradation of soil cover: Proceedings of the III International ScientificPractical Conference, 2007; 31-35.

24. Bakina, L.G., M.V. Chugunova, T.B. Zaitseva and Z.P. Nebol'sina, “The effect of liming on the complex of soil microorganisms and the humus status of a soddy-podzolic soil in a longterm experiment”. Eurasian Soil Science, 2014; 47(2): 110-118.

25. Shen, Z.-J., Y.-P. Wang, Q.-Y. Sun and W. Wang, "Effect of Vegetation Succession on Organic Carbon, Carbon of Humus Acids and Dissolved Organic Carbon in Soils of Copper Mine Tailings Sites”. Pedosphere, 2014; 24(2): 271-279.

26. Tisdall, J.M., "Organic matter and water-stable aggregates in soil”, Soil Sci, 1982; 33: 141-163.

27. Shvets, T.V., Modern assessment of soil fertility in agro-ecological monitoring of the low-land agricultural landscape for agro-ecological monitoring. The Polythematic Internet Electronic Scientific Journal of the Kuban State Agrarian University, 2009; 3: 125-136.

28. Tuev, N.A., Microbiological processes of humus formation. Moscow: Agropromizdat, 1989; 239. 